\title{
Noise and Neurons: Effects of Background Music on Reading Comprehension
}

\author{
Olivia Adams \\ Belmont University (B.S. in Entertainment Industry Studies, 2018) \\ Meredith McNair \\ Belmont University (B.S. in Entertainment Industry Studies, 2017) \\ This paper was presented at the 2018 International Summit of the \\ Music \& Entertainment Industry Educators Association
}

March 22-24, 2018

https://doi.org/10.25101/18.36

\section{Abstract}

Listening to music is a common activity among young adults, especially while studying or working on other school related activities. It is easy to observe this phenomenon among college campuses: students are sitting with their computers open, earbuds in, and pencil moving. Is it good or healthy for students to have this much noise with their rigorous schedules? Is it possible for them to be more or less productive depending on the genre of music they are listening to while working? Or does music have little to no measurable effect on the student's productivity? These are the questions that sparked an interest in this topic.

For this research study, an experiment comprised of eight focus groups with 33 people, aged 18-25, was conducted. During the experimental focus groups, three reading comprehension quizzes were administered; one was conducted without any music playing, the second with classical music, and the third with pop music. The quizzes each had a maximum score of 11 points. The mean for each quiz is as follows: silence 8.09 points, classical 8.76 , and pop 8.27. Out of the 33 individuals in this study, 31 had at least one score affected by music playing in the background.

Keywords: music and reading comprehension, attention drainage effect, background music and reading, music and studying, college study habits

\section{Introduction}

Spotify is playing in the background while you are studying for your chemistry midterm at the kitchen table in your apartment. You're nodding along to the beat of Taylor Swift's newest release while you try to balance the chemical equation that you have been stuck on for a while. You start tapping your pencil to the beat and softly humming along with the chorus as you continue to stare at the page filled with eraser marks, crossed out numbers, and chemical symbols. Before you know it, Taylor's song is over and it's on to the next song while you're still stuck on the same problem. You start wondering how many songs will play before you finish working on this one equation.

Music has many effects on the body, whether it is realized or not. It can change someone's mood and motivate them; it can be used to excite or calm a crowd. With apps like Spotify and Apple Music taking over the music scene, it seems as if people are always plugged in listening to their favorite song, the newest release from an artist, or a random song suggested by the app's algorithm. It is virtually impossible to make it through the day without hearing music in some form, and most people listen to music of their own accord, whenever they want, rather than just passing by and hearing something played.

Is it good or healthy for students to have this much noise with their rigorous schedules? Take a browse through Spotify and there are playlists for every occasion, from parties to workouts to relaxing to studying. Spotify even has ads about studying and partnerships with textbook rental companies like Chegg, showing that the service knows it is popular among the young college demographic and that many students are multitasking while listening.

Listening to music is a common activity among young adults, especially while studying or working on other school 
related activities. It is easy to observe this phenomenon among college campuses by strolling through the lawn, a common study space in a library, or even around the halls of academic buildings. Students are sitting with their computers open, earbuds in, and pencil moving. But, is the music actually helping students accomplish anything? Is it possible for them to be more or less productive depending on the genre of music they are listening to while working? Or does music have little to no measurable effect on the student's productivity? These are the questions that sparked an interest in this topic as well as the questions that will hopefully be answered by the end of this research study.

\section{Background}

This research is based on the Attention Drainage Effect Theory, which uses aspects from Kahneman's seminal research on attention. ${ }^{1}$ Kahneman, in his 1973 study, writes of a capacity model of attention where an individual can only exert a certain amount of attention at any given time, and that attention must be split between all tasks the individual is working on at that point in time. ${ }^{2}$ This particular research study is looking for data to show whether or not students exert part of their attention listening to the music instead of exerting all of their attention on the single task of taking a quiz. This study will be conducted in hopes of finding a correlation, whether positive or negative, between listening to music and the level of measurable concentration of students while reading. One such study has been published, but only 25 people participated and the focus of the research was more highly concentrated on the volume of the music than the genre. ${ }^{3}$ This study is aiming to recreate the Thompson study, but with quantitative data and a larger sample group.

\section{Literature Review:}

\section{Listening and Music}

Certain studies suggest that there are indeed benefits of listening to music and that music connects both sides of the brain. Listening to music changes or enhances specific neural circuits, including the ones that are connected to the auditory cortex, which can enhance how a person perceives things. In a 2014 study, Price relays the information that listening to music while studying is very similar to riding a bike or learning how to play a musical instrument, in the sense that the younger a person starts to learn, the easier it is to do later and throughout life. ${ }^{4}$ The findings state that if someone learned to study or take a test while listening to music in the past, it will be easier, and probably more helpful to them, rather than doing both for the first time as a college student. This finding is corroborated in a different study, which claimed that subjects who tested as more creative, "right brain" people, listened to music more often while completing other tasks, and thus, it was easier for them to concentrate with background music. ${ }^{5}$ As a factor of this current study, a brief profile of each participant was used to assess whether or not each participant listens to music while they study and how often they do so.

\section{Listening Styles}

Scores could also be affected by the way in which participants listen to the music, which may change across genres. Previous research divides these various listening styles into five categories: associative, cognitive, physical, involvement, and enjoyment. If the student is using the involvement style of listening, their "attention wanders from the music," creating a more "passive" experience. The student could instead use an associative listening style, which is a highly involved listening style, as the listener is experiencing "mental pictures" and connects the mood of the music to "events or objects of interest" to them. ${ }^{6}$

This study presumes that quizzes taken while listening to classical music will have a higher overall score than those listening to popular music. However, if a participant is using a more engaged listening style while classical music is playing and a passive listening style when popular music is playing, this participant's results could deviate from the expected results. This is because the amount of attention spent listening to each genre of music is not what most subjects would typically exert. The same deviation in results could be found if a participant used identical listening styles for each genre of music, that is, exerting the same amount of energy listening to each genre, could make the scores across genres identical. The results would be inconclusive, as there would be no deviation in any scores, meaning this subject could perform equally well under a variety of circumstances. The current study anticipates a minimal number of participants will achieve the same score on each quiz, as the majority of people will listen to different genres of music in different ways.

The experience could also be changed by the listener's preferences in music. They could listen more or less intently, depending on the genre, artist, or song. Previous research has concluded that concentration levels are altered differently based on the subject's likes and dislikes in background music, which led them to hypothesize that differences in test scores "increases with the intensity of listener feelings regarding the background music." This finding will be addressed by the demographic analysis conducted for this study. The subject's profiles will be compared with their scores to determine whether preferences in genre affected test scores, and if so, whether the background music had a positive or negative influence. It is not clear whether a positive or negative emotion associated with the music will have a stronger impact on scores, or if there is little to no noticeable impact on scores. 


\section{Personality Traits}

A fascinating study that has been recreated multiple times suggests the subject's personality traits could determine whether or not music will affect their test scores. Researchers have found that background music affects introverts and extroverts differently, which leads to differences in test scores, demonstrating scores could actually be improved with specific music for extroverts, while introverts saw an overall decline in test scores of reading comprehension. ${ }^{8}$ This factor will also be addressed in a participant profile to help distinguish between introverts and extroverts to see whether or not these results are replicated in the current study.

\section{Hypothesis}

The hypothesis for this study, based on previous studies conducted in this area, is that music with lyrics will be the most distracting for students, followed by classical music or music with no words. The main evidence supporting this hypothesis comes from the neurological deficiencies of humans to efficiently multitask. The brain cannot process both the lyrics and the reading simultaneously and still be able comprehend each at the same level as when they are being processed individually. ${ }^{9}$ Kiger's study demonstrated that the scores of students listening to "low information-load" music, meaning something less complex for the ear to process, were higher than those with "high information-load" music. ${ }^{10}$ Some students are aware that music can serve as a distraction, rather than a tool, while studying. In a qualitative analysis of research subjects, almost half of the students reported music as being their biggest distraction while studying, but there was no significant effect found on test scores. ${ }^{11}$ Therefore, for the purposes of this study, it is believed that the test scores in the quiet environment will be higher than those with background music.

\section{Methodology}

For this research study, there were eight small focus groups held in which an experiment was conducted. Each focus group ranged in size from two to eight participants, aged 18 to 25. During these experimental focus groups, three reading comprehension quizzes were administered in the following sequence: one was conducted without any music playing, the second with classical music, and the third with pop music. The classical works that were used in the second condition were Debussy's En Bateau, Bizet's Intermezzo from Carmen Suite No. 1, and Chopin's Nocturne No. 2 in E flat Major, Op. 9, No. 2, with Debussy's First Arabesque and Beethoven's Moonlight Sonata as needed for extra time. Finally, the pop songs used as part of the third experimental condition were Feel It Still by Portugal. The Man, ...Ready For It? by Taylor Swift, Levels by Nick Jonas, There's Nothing Holdin' Me Back by Shawn Mendes, and What Lovers Do by Maroon 5 featuring SZA. To try and create the most accurate test results, the quizzes across different groups were conducted the same across both the silence and music conditions. The same songs were played during each session and were in the same order.

As in the 2009 Tze study, this study used practice tests for the Test of English as a Foreign Language, or TOEFL, in order to measure reading comprehension. The TOEFL test measures the English proficiency of students whose first language is not English, but who wish to study at universities that teach in English. Thus, it was an appropriate skill level for students in the 18-25 year old range because they are typically university students, and should have approximately the same level of English proficiency as those who would be taking the TOEFL test. Three practice tests, each with eleven multiple choice questions and between five and ten paragraphs, from the fourth edition of The Official Guide to the TOEFL Test, were chosen as the measurement tools for this study.

The tests were administered on Qualtrics, with a paper copy of the readings distributed. Each reading excerpt was printed on its own sheet of paper that was distributed immediately before the beginning of each quiz in order to prevent participants from reading ahead, which could lead to skewed results. A demographic analysis was conducted (Appendix 1) before the experiment began to see if the results were more significant based on sex, race, music interests, whether or not the subject listens to music while studying or taking tests on a regular basis, and personality traits. Participants were also timed to see if certain quizzes took significantly more or less time.

\section{Results:}

\section{Subject Profile}

In total, 33 people, 17 males and 16 females, took part in this research study. The three quizzes used each had a maximum score of 11 . The mean score for the quiz taken in silence was 8.09 with a standard deviation of 1.85 (see Figure 1 on the next page). For the classical music quiz, the mean score was 8.76 with a standard deviation of 1.72 (Figure 2). The mean for the pop music quiz was 8.27 with a standard deviation of 2.06 (Figures 3-5).

Nineteen people reported regularly listening to music while studying. The values were almost evenly spread among the individuals in terms of the years spent training themselves to listen to music as a study tool (Figure 6).

There were slightly more people who reported listening to music while studying for one to three years, which aligns with the beginning of college for most, if not all of the respondents, suggesting that it is possible these students begin listening to music while studying more regularly when they become independent college students. In regards to person- 


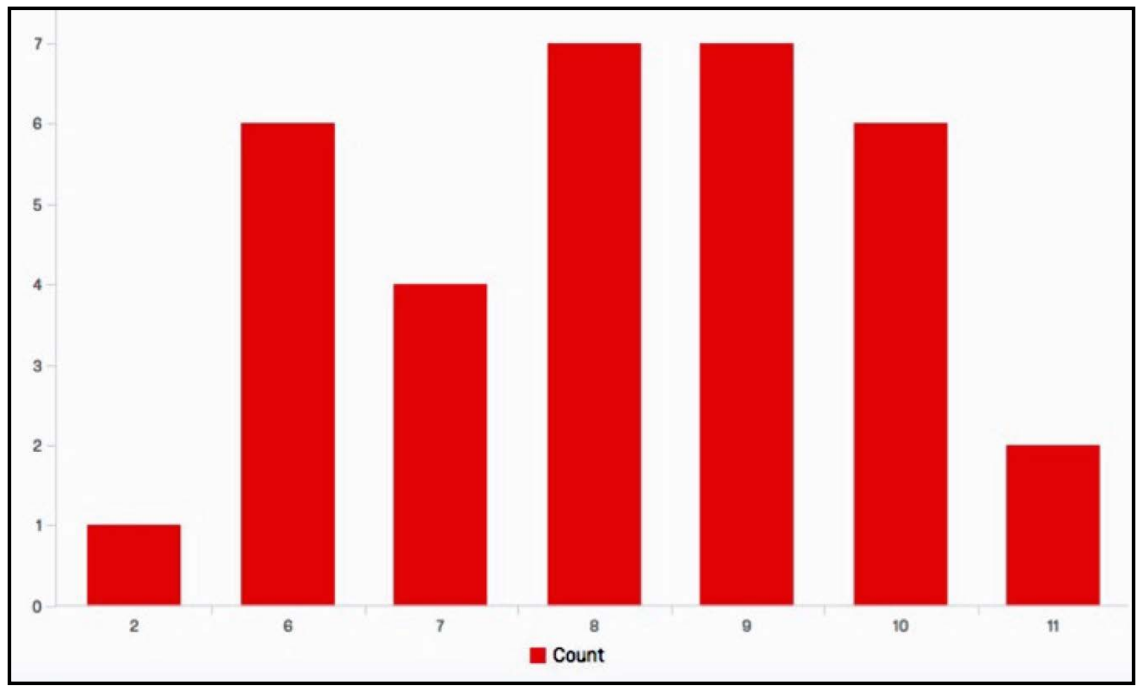

Figure 1. Score results from Quiz 1: Silence (x-axis represents score, y-axis represents number of participants). Mean: $8.09 \mathrm{SD}: 1.85$.

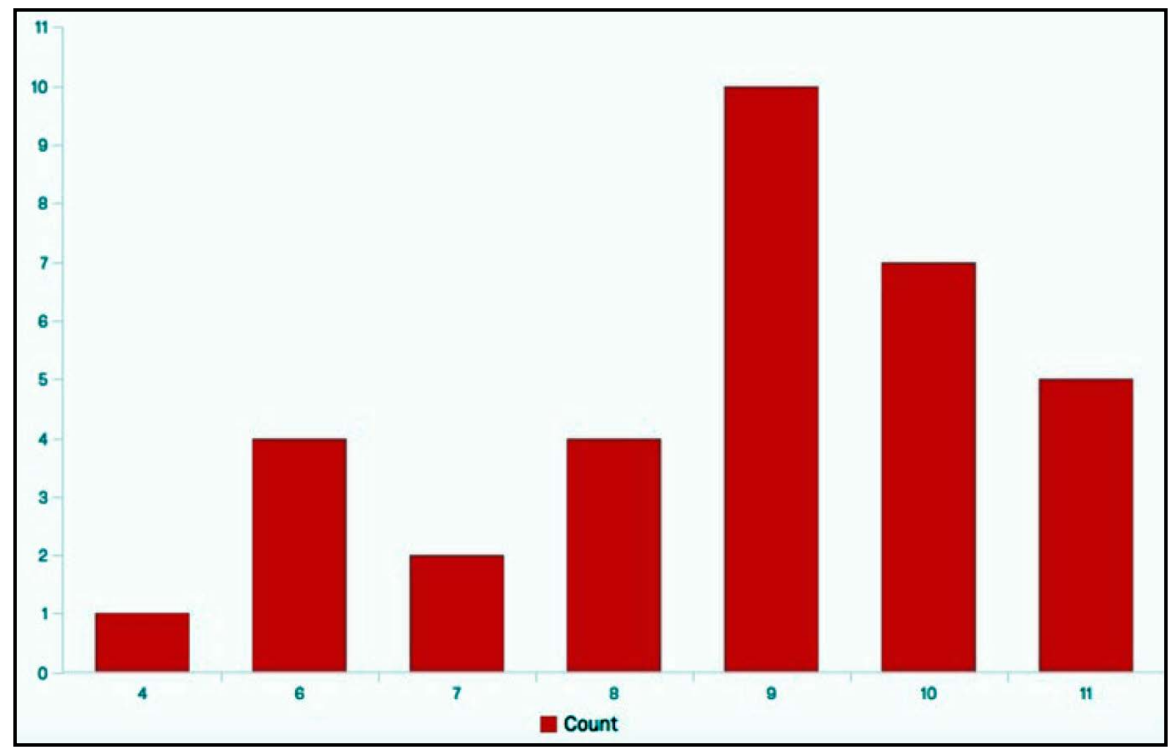

Figure 2. Score results from Quiz 2: Classical music (x-axis represents score, $y$-axis represents number of participants). Mean: 8.76 SD: 1.72.

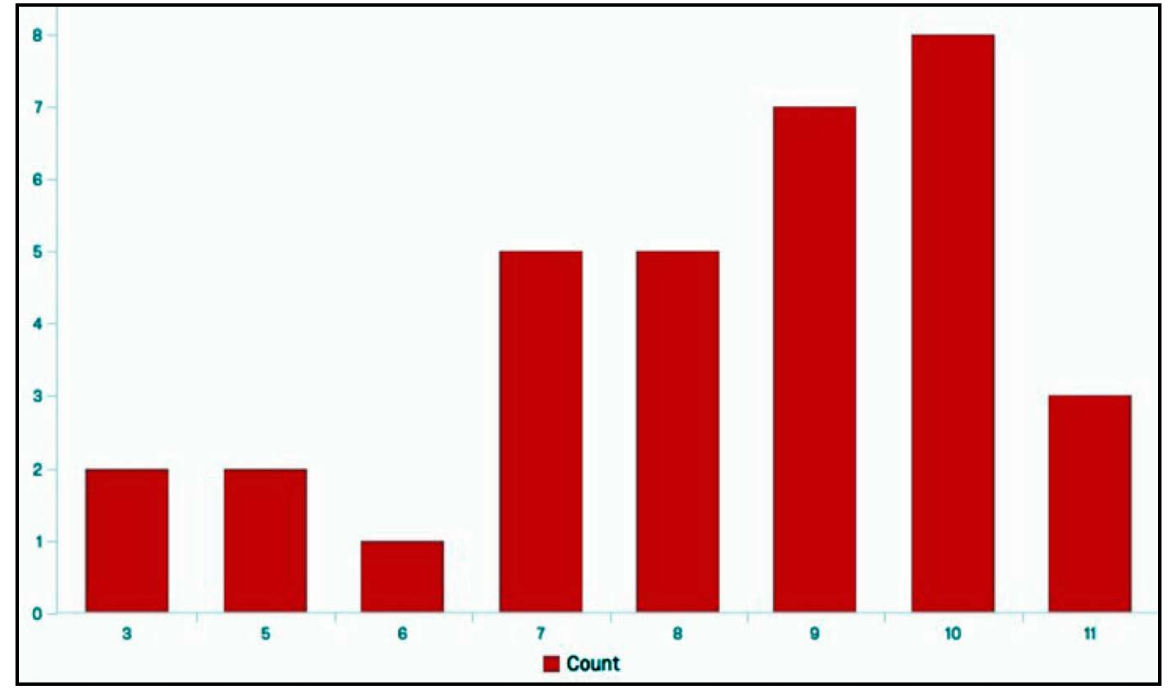

Figure 3. Score results from Quiz 3: Pop music (x-axis represents score, y-axis represents number of participants). Mean: 8.27 SD: 2.06. 


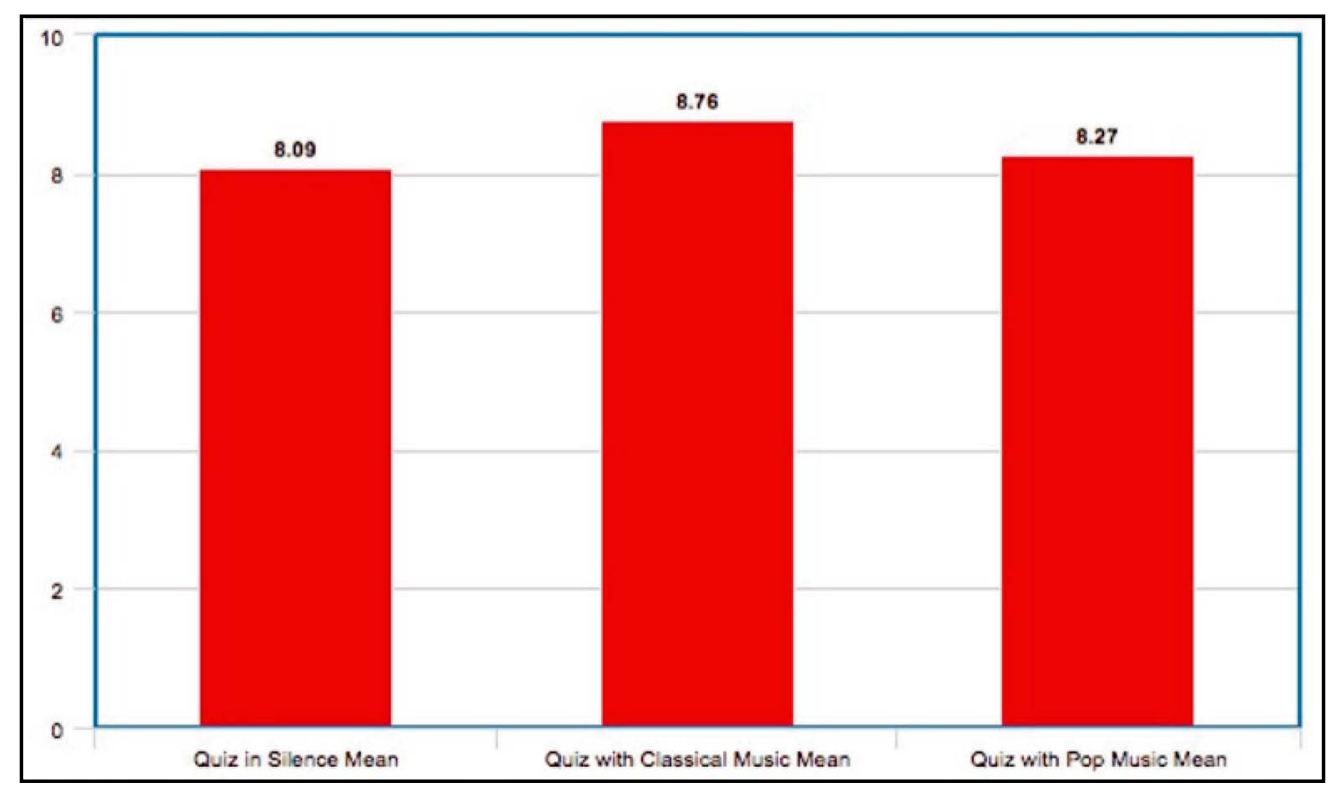

Figure 4. Comparison of Means.

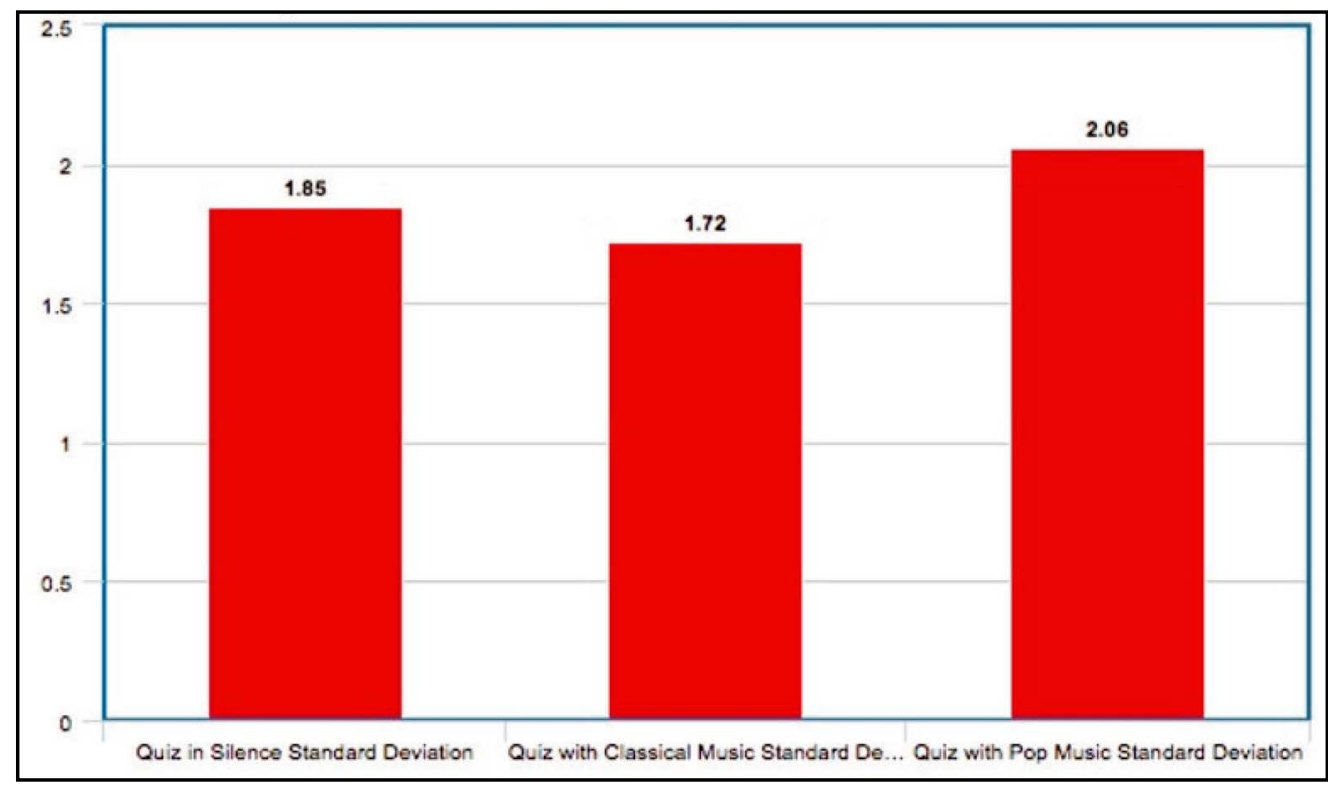

Figure 5. Comparison of Standard Deviations.

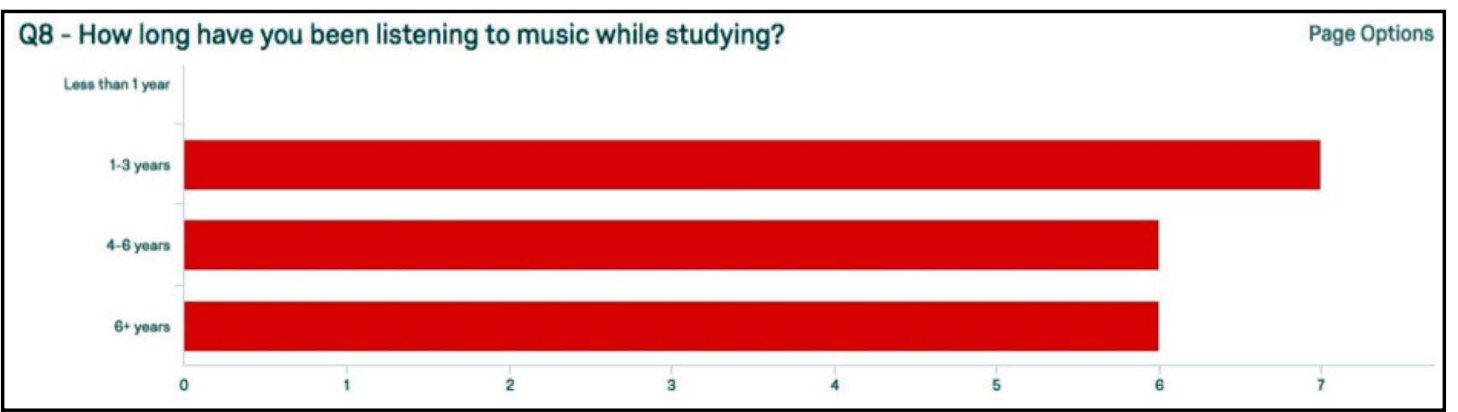

Figure 6. Years spent listening to music 


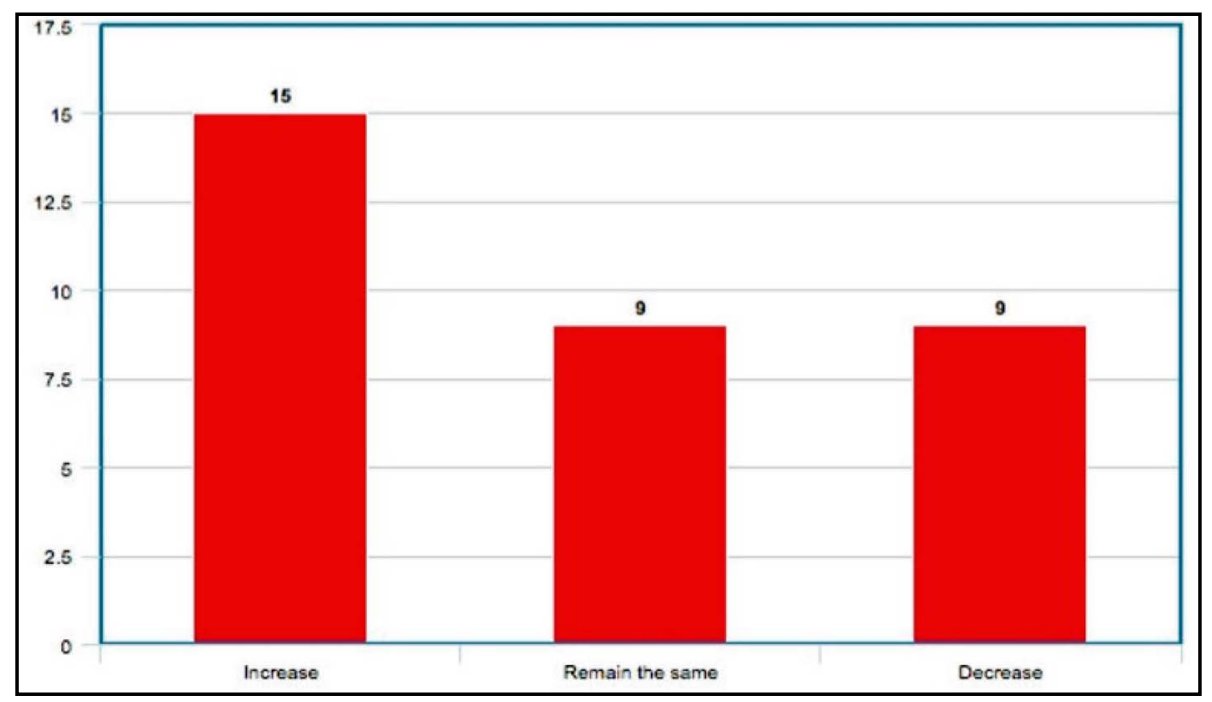

Figure 7. Classical scores compared to silent scores.

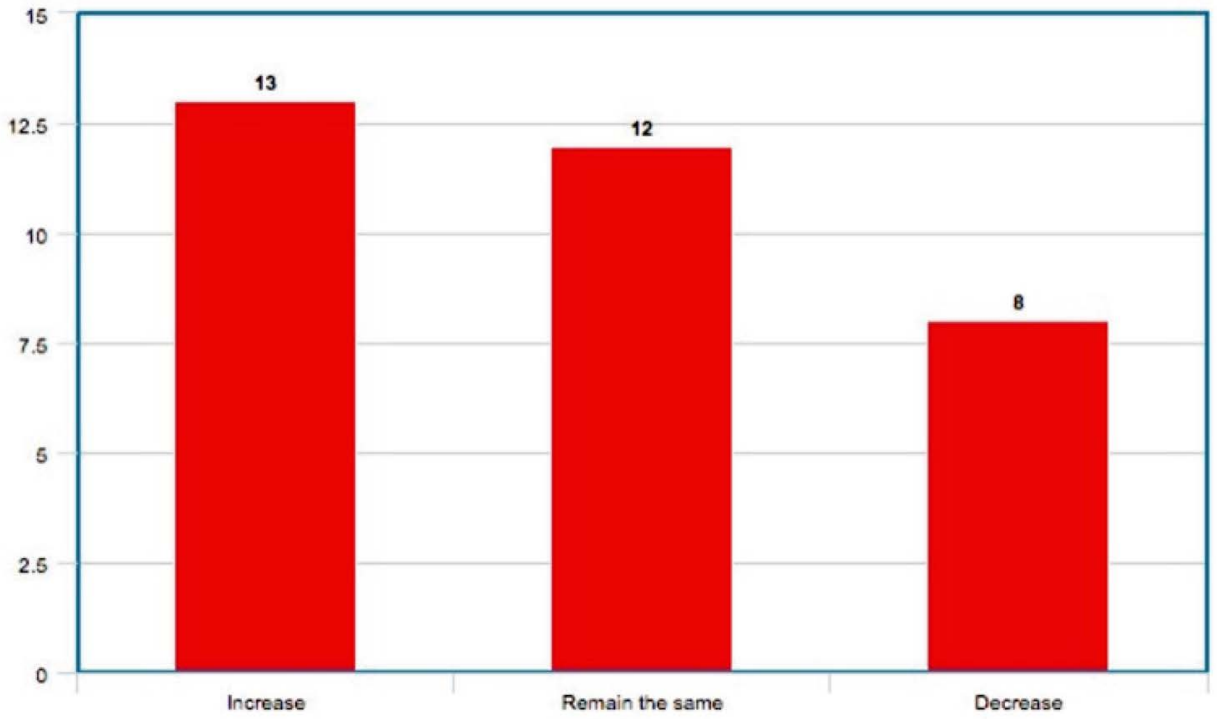

Figure 8. Pop scores compared to silent scores.

ality traits, 23 people reported being introverted, while only 10 identified as being extroverted.

\section{Music Listening Conditions}

Out of the 33 individuals in this study, 31 of them had at least one score affected by music playing in the background. During the classical music section of the study, as compared to the results in a quiet environment, 15 scores increased, 9 remained the same, and 9 decreased (Figure 7). In the pop music section, relative to the scores in a quiet environment, 13 scores increased, 12 remained the same, and 8 decreased (Figure 8 ).

Only two participants had all three scores remain constant during each quiz and, interestingly, neither reported having experience listening to music while performing school-related tasks.
The most astounding correlation is with the Price study, which claimed that experience listening to music while studying would keep results constant, or possibly improve them, and the opposite with inexperience. This study found that out of the 33 participants, 20 showed improvement in their scores, which aligned with this result. More remarkable than this, out of the 19 individuals who reported that they do regularly listen to music while studying, 15 experienced an increase in at least one of their quiz scores when music was playing. This shows a strong correlation and the possibility to train oneself to perform better in certain circumstances, or simply to block out noise better. Because experience listening to music has been shown to be such a large factor in test scores with music playing, the piece of our hypothesis that predicted scores to be highest in silence 
was, in fact, disproven.

With experience listening to music, scores generally improved during the classical music section, replicating findings in the Kiger study in relation to the effects of "low-information load music" as compared to "high-information load music." 12 Even if participants had no experience listening to music, the average score was higher while listening to classical music than listening to pop music, demonstrating the different impacts each form of music can have. If participants had years of experience listening to high-information load music while studying, such as pop or EDM, their scores generally did not follow this trend, and instead aligned more closely with the results from Price's 2014 study. As predicted, there was a large range in scores during the pop music section of the study. This was the largest variance value in the scores at 4.26 points.

\section{Personality Types: Introvert vs. Extrovert}

Each subject was asked on the profile sheet whether they considered themselves an introvert or an extrovert, as this personality trait could possibly coincide with their results. The results in this aspect of the research did not show an overwhelming amount of correlation, as many of the subjects had years of experience studying with background music. This was found to outweigh the implications personality traits could have on music. Only 11 participants, or one third of those tested, exhibited the idea found in the Dobbs, Furnham, and McClelland study that extroverts performed better with fast and loud music (e.g., pop), and introverts performed better with slow or no music playing. Compared to personality traits, experience listening to music while studying seems to be a factor that weighs more heavily on reading comprehension scores. Personality traits, in this study, appeared to merely serve as a buffer that helped keep scores constant. There is a possibility personality traits could improve scores, but this was not found reliable in this study. If there was an increase found in someone's score, the improvement was slight.

\section{Conclusion}

The most phenomenal new finding in this study was the comparative change in scores between males and females when music was playing. Since the majority of participants listened to music while studying, most test scores remained constant or improved while music was playing. While classical music was playing, the average score for both males and females increased; the average male score increased by 0.64 points and the female score by 0.62 points, relative to in the silent condition. While pop music was playing, male scores still improved, on average by 0.41 points, but the average female score decreased by 0.13 points in comparison to the silent score (Figure 9).

This finding was not discussed in prior studies, but could be a point of further research. A possible explanation for this finding may be the sociological phenomenon that women are taught to be subdued, while men are encouraged to be loud and outgoing, thus creating a finding that may be similar to that of Dobbs et. al, but instead correlating scores to learned personality behaviors instead of innate personality traits.

No conclusive results were found regarding listening styles and preference of musical genre while studying. The main factor contributing to this is that vast majority of participants indicated their preferred style of music was different than the two played during this study, so this facet was unable to be tested. Out of the few results that were

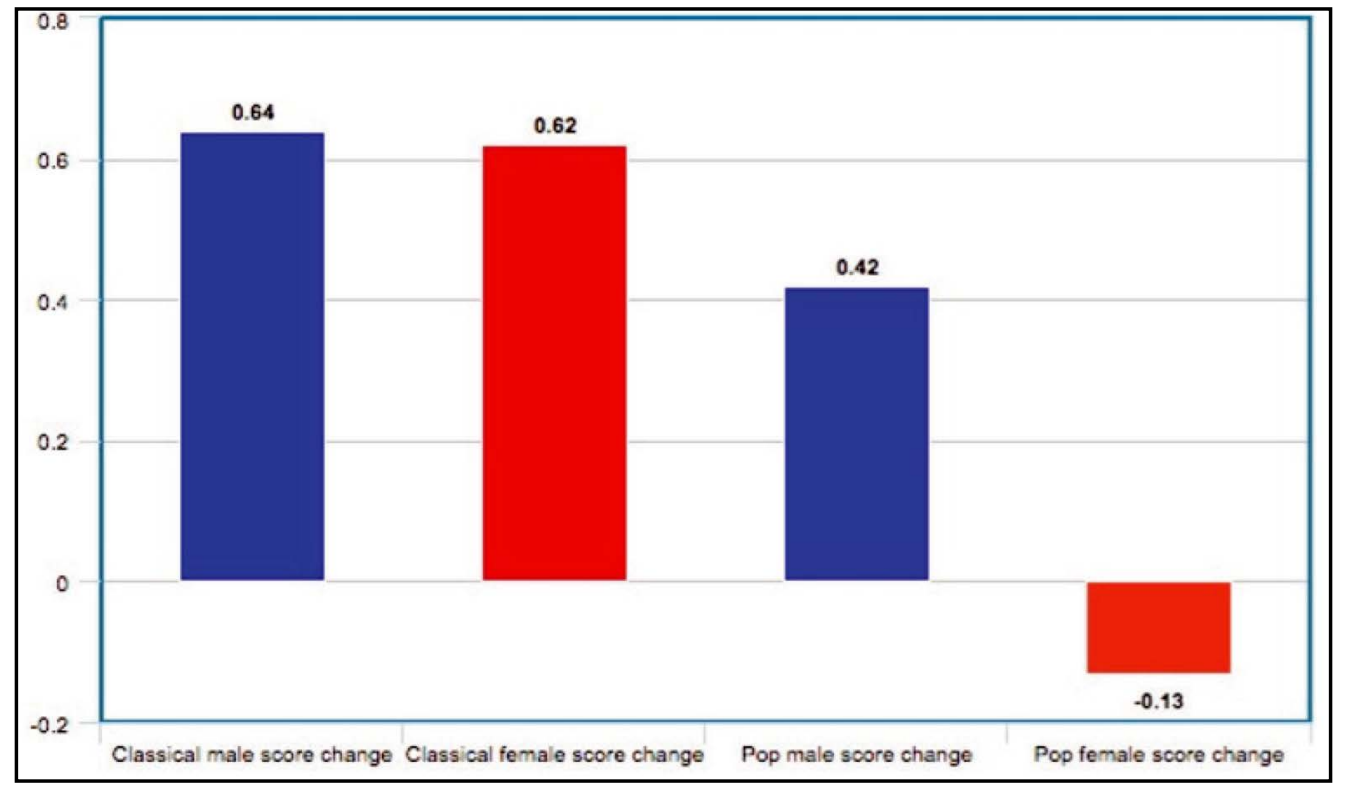

Figure 9. Comparison of Male and Female Scores. 
obtained, the data seem to suggest that an interest in the music being listened to can lead the student to be more involved in listening to background music than music they find uninteresting. However, only seven people indicated their favorite style of music was either pop or classical. Out of these seven people, five performed worse when their preferred genre was playing. If this study were to be conducted again, it would be beneficial to inquire about preferred musical styles before the experiment so that this aspect of research could be more accurately studied.

Overall, the findings of this study in regards to those unfamiliar with listening to music while studying are consistent with Kahneman's Theory of Attention, suggesting that a person is only capable of exerting a set amount of attention, and this must be split between all tasks to be simultaneously performed. This finding also lends itself to the Attention Drainage Effect Theory, described in the Tze study, furthering the idea that attention cannot grow, but must rather be split between all possible tasks. Since those who participated in this study were past their formative years, this theory suggests it is unlikely for those who have little to no experience studying while listening to music can improve their skills enough to be comparable to those who have years of experience listening to music and studying.

The last factor studied was the amount of time it took each person to complete the quizzes in each music condition. Even if scores were unaffected, this study was looking for an indication of whether or not people have to work harder to maintain them under different circumstances. The average time for the silent quiz was 9:04. The classical music average quiz time was a bit lower at 8:32. However, the pop music average quiz time was higher than both other conditions at 9:17 (Figure 10).

Thus, even if someone's scores were unaffected by the music, the amount of time spent on the pop music quiz was generally higher. While a student may be able to perform at an equal level to working in silence while music is playing, it may take them longer to do so, making it more efficient for them to work in silence.

This study suggests that whether or not someone has experience listening to music while studying is the most influential factor in determining whether or not their scores will be affected by background music. There may be other factors that play a lesser part in this, such as personality traits, preferences in music, and listening styles, but these were found to have a smaller impact, if any, on the resulting scores of the tested individuals. Although scores may not be affected by music playing, it could take someone much longer to complete a task with background music, even if they do have experience listening to music while studying. The main takeaway from this study is that students should conclude it is best for them to keep their study habits the same. This, rather than trying to change the study methods that they are used to, because noise can indeed affect the work their neurons are doing.

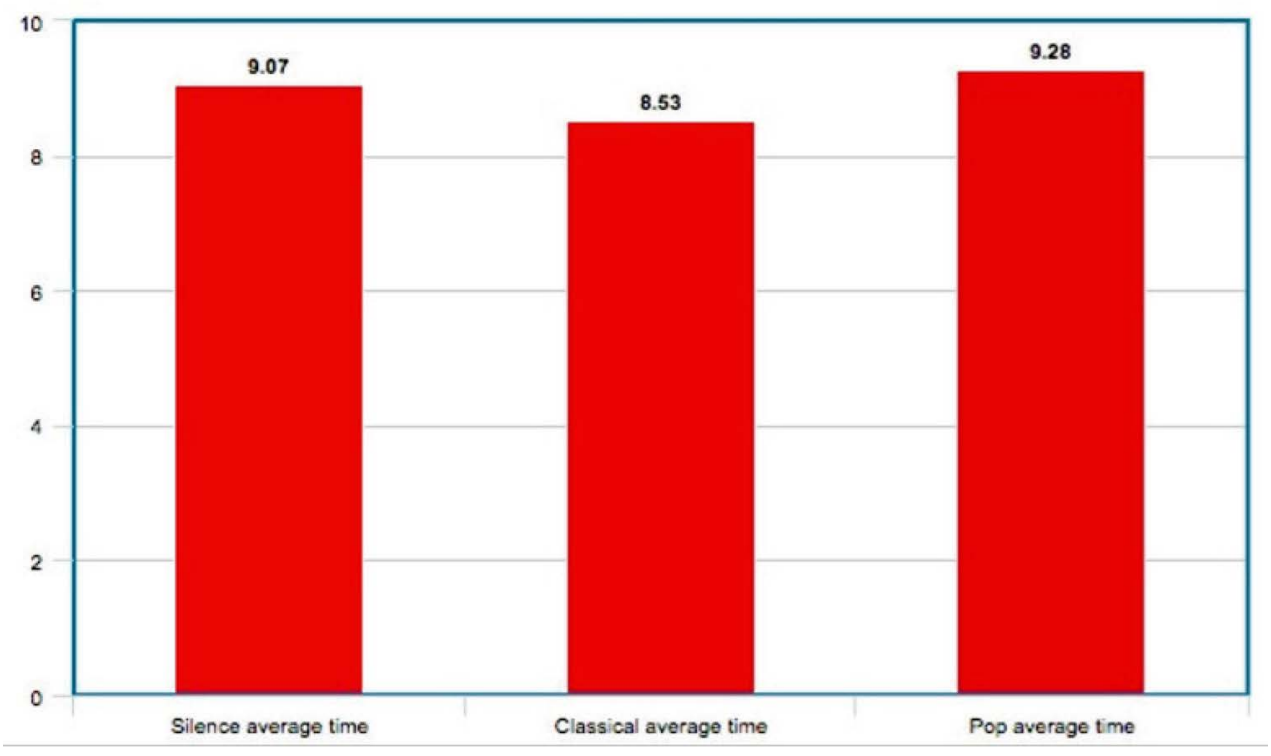

Figure 10. Average quiz times. 
Q1 What is your name?

Q2 What is your age?

$\square$ 18-19 (1)

$20-22$ (2)

$\square 23-25$ (3)

Q3 What is your gender?

$\square$ Male (1)

$\square$ Female (2)

$\square$ Non-binary (3)

$\square$ Other (4)

Q4 What is your race?

$\square$ American Indian or Alaskan Native (1)

$\square$ Asian (2)

$\square$ Black or African American (3)

$\square$ Native Hawaiian or Other Pacific Islander (4)

White (5)

$\square$ Mix of 2 or more (6)

$\square$ Other (7)

Q5 What is your favorite type of music to listen to?

$\square$ Classical (e.g., Beethoven, Mozart) (1)

$\square$ Country (e.g., Blake Shelton, Carrie Underwood) (2)

$\square$ Folk (e.g., Alison Krauss, Bob Dylan) (3)

$\square$ Pop (e.g., Nick Jonas, Taylor Swift) (4)

$\square$ Rock (e.g., AC/DC, Rolling Stones) (5)

$\square$ Other (6)

Q6 Do you regularly listen to music while you study?

$\square$ Yes (1)

$\square$ No (2)

Skip To: Q9 If Do you regularly listen to music while you study? $=$ No
Q7 What is your favorite type of music to listen to while studying?

$\square$ Classical (e.g., Beethoven, Mozart) (1)

$\square$ Country (e.g., Blake Shelton, Carrie Underwood) (2)

$\square$ Folk (e.g., Alison Krauss, Bob Dylan) (3)

$\square$ Pop (e.g., Nick Jonas, Taylor Swift) (4)

$\square$ Rock (e.g., AC/DC, Rolling Stones) (5)

$\square$ Other (6)

Q8 How long have you been listening to music while studying?

$\square$ Less than 1 year (1)

$\square$ 1-3 years (2)

$\square$ 4-6 years (3)

$\square 6+$ years (4)

Q9 Are you an introvert or extrovert?

$\square$ Introvert (1)

$\square$ Extrovert (2) 


\section{Endnotes}

1. Peter Tze and Ming Chou, "Attention Drainage Effect: How Background Music Effects Concentration in Taiwanese College Students," Journal of the Scholarship of Teaching and Learning 10, no. 1 (2010): 44, accessed September 7, 2017. https://eric.ed.gov /?id=EJ882124.

2. David Kahneman, Attention and Effort (Englewood Cliff: Prentice Hall, 1973), 8, accessed September 6, 2017. https://pdfs.semanticscholar.org/eeb9/7f210404ca6758c6cfe41cbe552feed5f59e.pdf.

3. William Forde Thompson, E. Glenn Schellenberg, and Adriana Katharine Letnic, "Fast and Loud Background Music Disrupts Music Comprehension," Society for Education, Music, and Psychology Research 40, no. 6 (2012): 703 , accessed 13 September 2017. https://doi. org/10.1177/0305735611400173.

4. Amy Price, "Music For Thinking; Does Music Help You Study?" IThinkWell.org, last modified April 3, 2013. http://www.ithinkwell.org/music-for-thinkingdoes-music-help-you-study/.

5. Maddie Doyle and Adrian Furnham, "The distracting effects of music on the cognitive test performance of creative and non-creative individuals," Thinking Skills and Creativity 7, no. 1 (2012): 5, accessed October 18, 2017, https://doi.org/10.1016/j.tsc.2011.09.002.

6. Steven Hedden, "Listeners' Response to Music in Relation to Autochthonous and Experiential Factors," Journal of Research in Music Education 21, no. 3 (1973): 228 , accessed October 18, 2017. https://doi. org/10.2307/3345092.

7. Rong-Hwa Huang and Yi-Nuo Shih, "Effects of background music on concentration of workers," Work 38, no. 4 (2011): 386, accessed October 18, 2017. https:// doi.org/10.3233/WOR-2011-1141.

8. Stacey Dobbs, Adrian Furnham, and Alastair McClelland, "The effect of background music and noise on the cognitive test performance of introverts and extraverts," Applied Cognitive Psychology 25, no. 2 (2011): 311, accessed October 18, 2017. https://doi. org/10.1002/acp.1692.

9. Nick Perham and Harriet Currie, "Does listening to preferred music improve reading comprehension performance?" Applied Cognitive Psychology 28, no. 2 (2014): 279, accessed October 18, 2017. https://doi. org/10.1002/acp.2994.

10. Derrick M. Kiger, "Effects of Music Information Load on a Reading Comprehension Task," Perceptual and Motor Skills 69, no. 2 (1989): 531, accessed October 18, 2017. https://doi.org/10.2466/pms.1989.69.2.531.

11. Larry D. Rosen, L. Mark Carrier, and Nancy A. Cheever, "Facebook and texting made me do it:
Media-induced task-switching while studying," Computers in Human Behavior 29, no. 3 (2013): 955, accessed October 18, 2017. https://doi.org/10.1016/j. chb.2012.12.001.

12. Derrick M. Kiger, "Effects of Music Information Load on a Reading Comprehension Task," Perceptual and Motor Skills 69, no. 2 (1989): 531, accessed October 18, 2017. https://doi.org/10.2466/pms.1989.69.2.531.

\section{References}

Dobbs, Stacey, Adrian Furnham, and Alastair McClelland. "The effect of background music and noise on the cognitive test performance of introverts and extraverts." Applied Cognitive Psychology 25, no. 2 (2011): 307313. https://doi.org/10.1002/acp.1692.

Doyle, Maddie, and Adrian Furnham. "The distracting effects of music on the cognitive test performance of creative and non-creative individuals." Thinking Skills and Creativity 7, no. 1 (2012): 1-7. https://doi. org/10.1016/j.tsc.2011.09.002.

Educational Testing Service. The Official Guide to the TOEFL Test, Fourth Edition. New York: McGraw-Hill, Inc, 2012.

Hedden, Steven. "Listeners' Response to Music in Relation to Autochthonous and Experiential Factors." Journal of Research in Music Education 21, no. 3 (1973): 225238. https://doi.org/10.2307/3345092.

Huang, Rong-Hwa, and Yi-Nuo Shih. "Effects of background music on concentration of workers." Work 38, no. 4 (2011): 383-387. https://doi.org/10.3233/WOR2011-1141.

Kahneman, David. Attention and Effort. Englewood Cliff: Prentice Hall, 1973. Accessed September 06, 2017. https://pdfs.semanticscholar.org/eeb9/7f210404ca6758c6cfe41cbe552feed5f59e.pdf.

Kiger, Derrick, M. "Effects of Music Information Load on a Reading Comprehension Task." Perceptual and Motor Skills 69, no. 2 (1989): 531-534. https://doi. org/10.2466/pms.1989.69.2.531.

Perham, Nick, and Harriet Currie. "Does listening to preferred music improve reading comprehension performance?" Applied Cognitive Psychology 28, no. 2 (2014): 279-284. https://doi.org/10.1002/acp.2994,

Price, Amy. "Music For Thinking; Does Music Help You Study?" IThinkWell.org, last modified April 3, 2013. http://www.ithinkwell.org/music-for-thinking-doesmusic-help-you-study/.

Rosen, Larry D., L. Mark Carrier, and Nancy A. Cheever. "Facebook and texting made me do it: Media-induced task-switching while studying." Computers in $\mathrm{Hu}$ - 
man Behavior 29, no. 3 (2013): 948-958. https://doi. org/10.1016/j.chb.2012.12.001.

Thompson, William Forde, E. Glenn Schellenberg, and Adriana Katharine Letnic. "Fast and Loud Background Music Disrupts Music Comprehension." Society for Education, Music, and Psychology Research 40, no. 6 (2012): 700-708. https://doi. org/10.1177/0305735611400173.

Tze, Peter, and Chou, Ming. "Attention Drainage Effect: How Background Music Effects Concentration in Taiwanese College Students." Journal of the Scholarship of Teaching and Learning 10, no. 1 (2010): 36-46. https://eric.ed.gov/?id=EJ882124.

Olivia Adams plans to graduate from Belmont University in December 2018 with a B.S. in Entertainment Industry Studies and a minor in Marketing. Outside of school, Adams works as a professional harpist and has a strong passion for classical music. After graduation, Adams is seeking a career in music or sports marketing. Previous accomplishments include being in the inaugural class of the Grammy Museum's Music Revolution Project in Kansas City, attending the $55^{\text {th }}$ annual Grammy Awards, interning with The Escape Game corporate marketing team, presenting at the 2018 MEIEA Summit, and being inducted into the Alpha Chi Honor Society. This paper was also selected to receive the Alfred Leland Crabb Award for Best Undergraduate Collaborative Work at Belmont University.

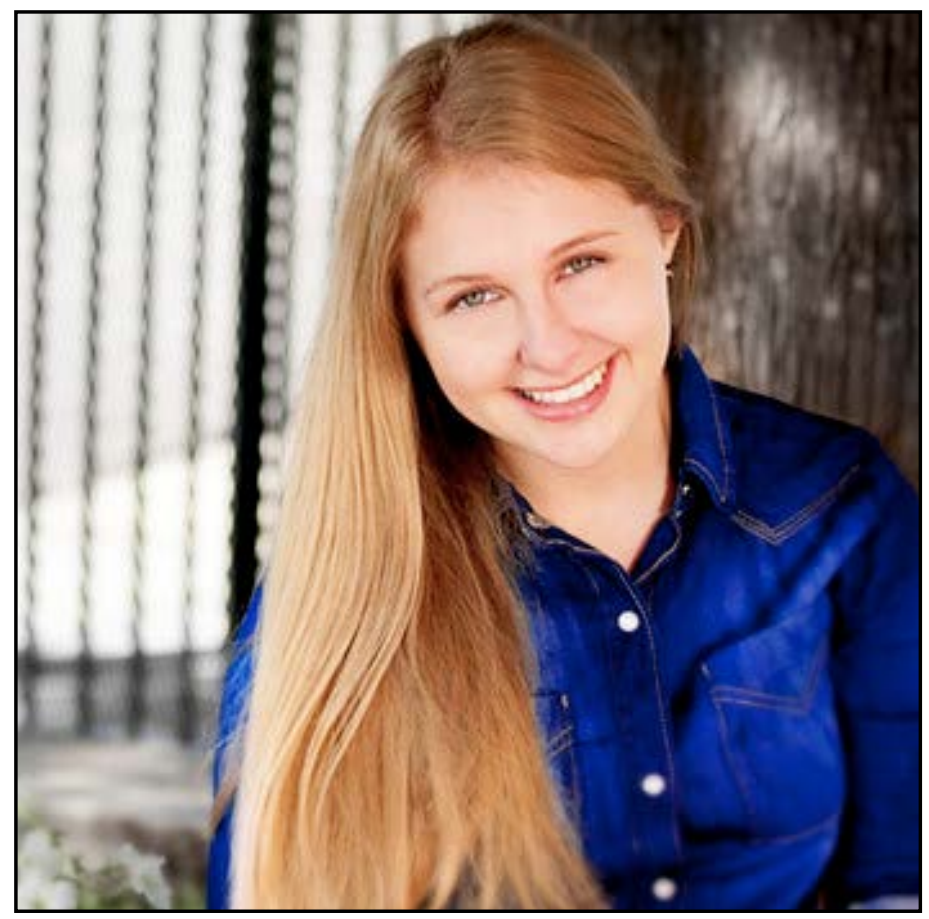

Meredith McNair is a 2017 graduate from Belmont University with a B.S. Degree in Entertainment Industry Studies and a minor in Business Administration. McNair is a songwriter, and the Promotions Coordinator at Cold River Records where she is assisting with the label's current artists, the Innovation in Music Awards (IMA), and the planned expansion of label artist activity. Originally from Dayton, Texas, she moved to Nashville in 2011 to pursue a songwriting career. Previous accomplishments include being one of ten attendees at the 2016 BMI Songwriting Retreat hosted by Sony/ATV, interning with The Orchard (Sony RED) and Triple Tigers Records, and now, having research included at the 2018 MEIEA Summit.

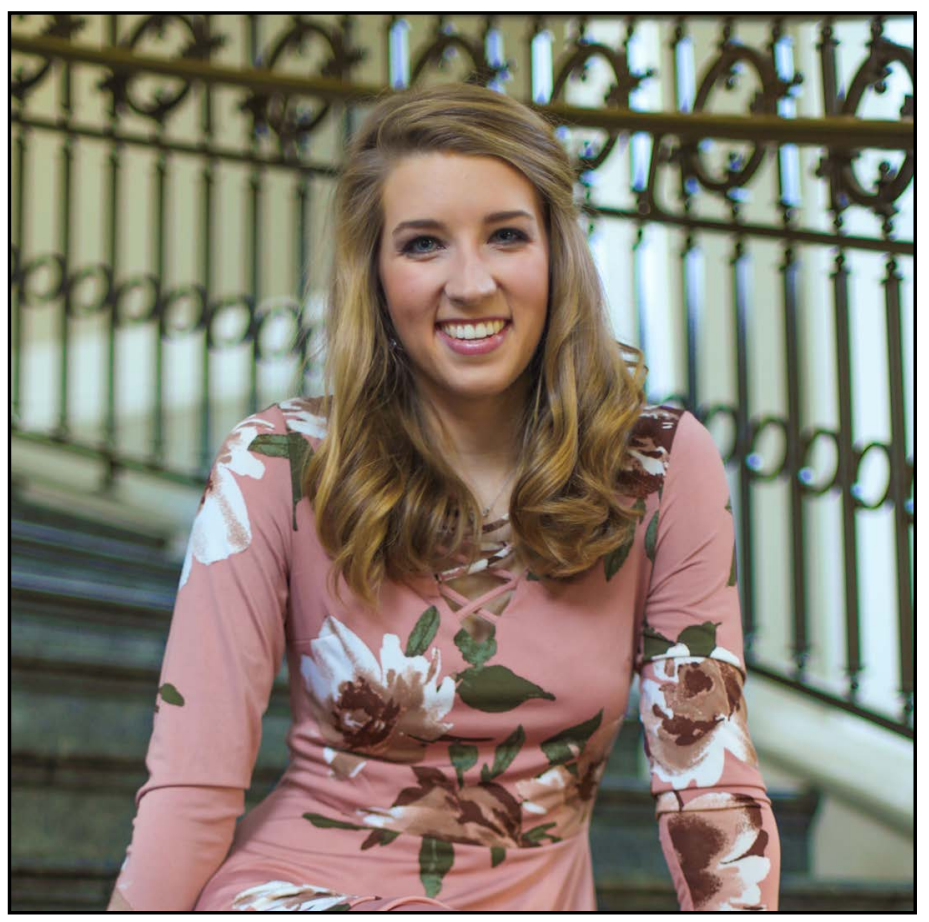




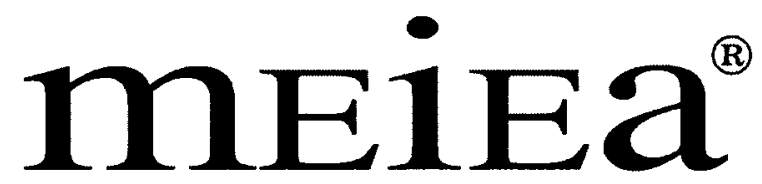

MUSIC \& ENTERTAINMENT INDUSTRY

EDUCATORS ASSOCIATION

\section{PROCEEDINGS OF THE \\ 2018 INTERNATIONAL SUMMIT}

OF THE

\section{MUSIC \& ENTERTAINMENT INDUSTRY EDUCATORS \\ ASSOCIATION}
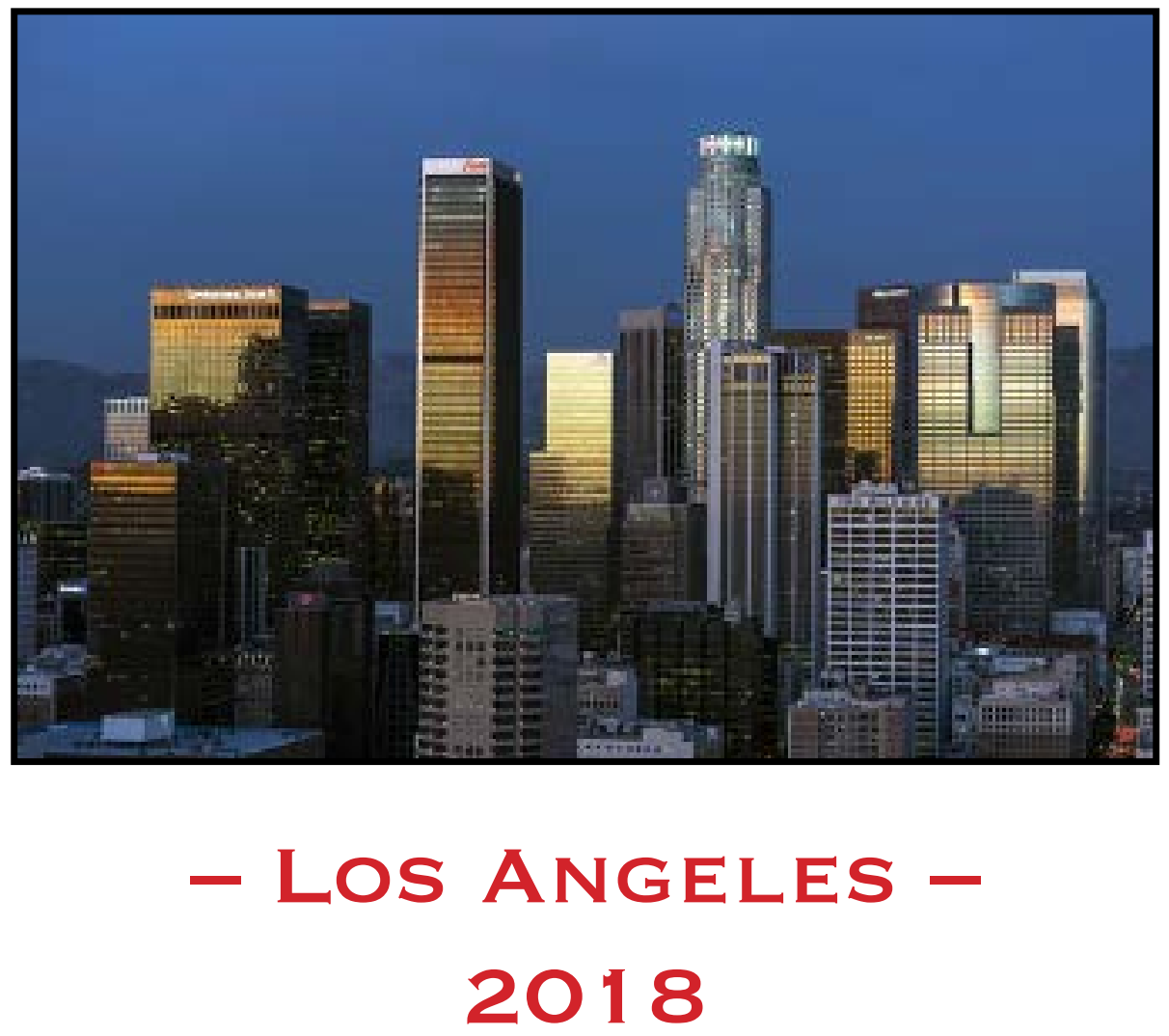

March 22 - 24, $2018 \cdot$ Embassy Suites by Hilton - Los Angeles/Glendale 